\title{
Gas dynamics and heat-and-mass transfer in multistage steam jet pumps with intermediate condensers
}

\author{
Yu. M. Brodov, K. E. Aronson, A. Yu. Ryabchikov, D. V. Brezgin, \\ I. B. Murmanskii \& N. V. Zhelonkin \\ Ural Power Engineering Institute, Ural Federal University named after \\ the first President of Russia B.N. Yeltsin, Russia
}

\begin{abstract}
To specify the gas dynamics physical model and the design methods for ejectors, as well as the intermediate coolers functioning features, a range of complications has been formulated. It has been proven that the coefficient defining the critical section position of the secondary stream and characterizing the entrainment ratio of the ejector first stage depends on the characteristics of "a sound pipe" zone. Within this zone the velocity of the secondary stream can exceed sonic speed while the shock waves in the primary stream decrease. The optimum axial dimensions of the ejector are determined by the characteristics of "a sound pipe". The experimental investigations results reveal that the flow rate portion of steam condensed in the first stage cooler is about $70-80 \%$ of the full flow rate of steam entering the cooler and virtually doesn't depend on the air content in steam. The cooler efficiency depends on steam pressure, which is determined by the performance of the subsequent stage ejector and also by the cooling water temperature and flow rate.

Keywords: multistage steam-driven ejector, mixing chamber, intermediate cooler, ejector operation performance.
\end{abstract}

\section{Introduction}

Multistage steam-driven ejectors with inter-condensers are intended to maintain the low pressure $(\mathrm{Pk}=3 \ldots 5 \mathrm{kPa})$ in the steam turbine condensers. The ejectors remove the air (the steam-air mixture - SAM) from the condenser into the 
atmosphere. The high air compression ratio is achieved by the SAM condensation in the intermediate coolers. The principle scheme of a multistage ejector with intermediate coolers is presented in Fig. 1.

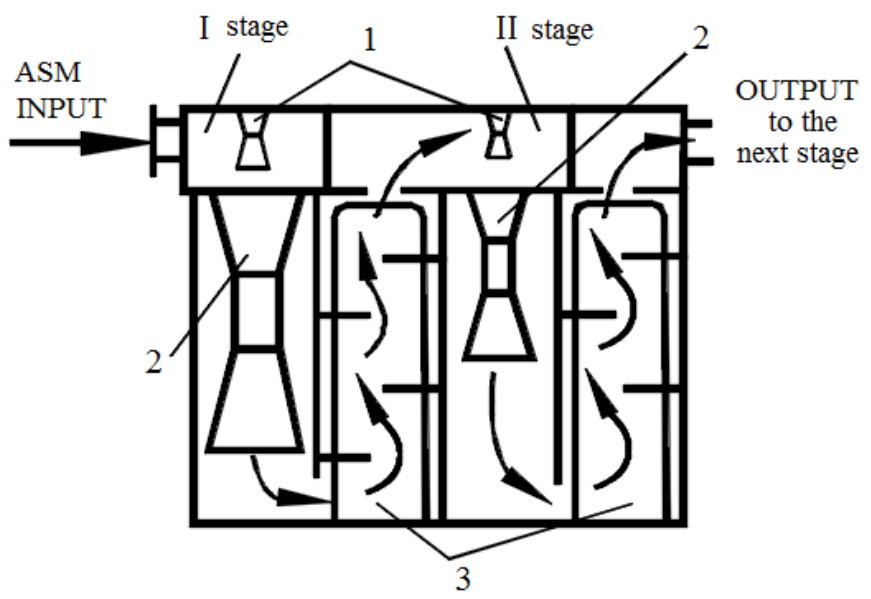

Figure 1: The principle scheme of a multistage steam-driven ejector functioning 1 - primary nozzle, 2 - mixing chamber, 3 - intermediate cooler.

Shown in Fig. 2 are the experimental data and the results of the operation performance calculations for the first and second stages of a steam turbine threestage ejector (calculated for an atmosphere air as a secondary stream). The points indicate the results of the corresponding parameter measurements.

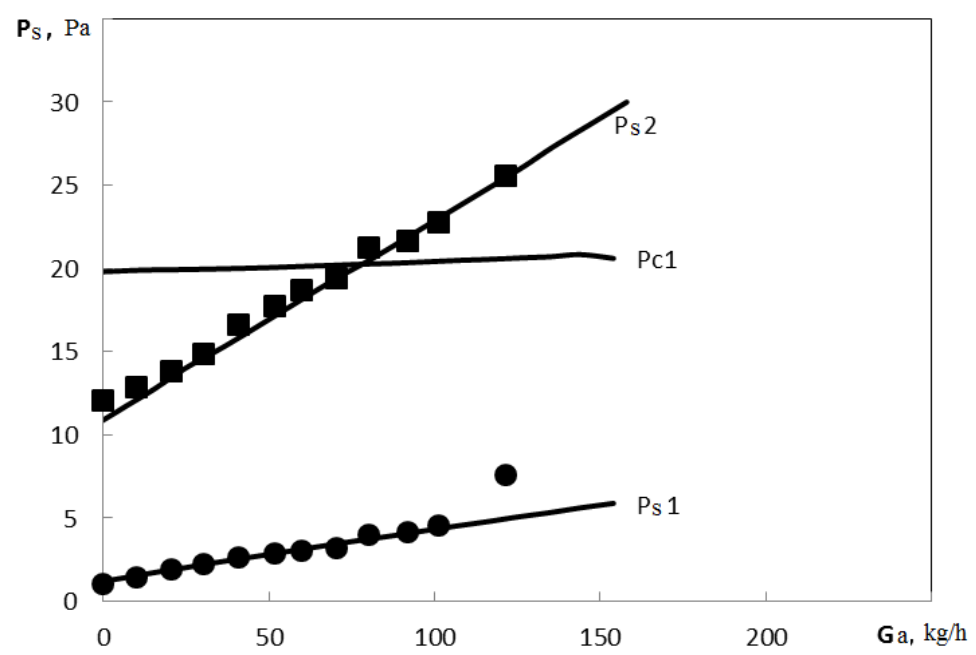

Figure 2: The ejector operation performance curve for dry (atmosphere) air: $P_{\mathrm{s} 1}$, $P_{\mathrm{s} 2}-$ calculated pressure of suction for the I and II ejector stages; $P_{\mathrm{c} 1}$ - critical backpressure of the I ejector stage. 
As shown in Fig. 2, calculated operation performances of the first and the second stages correspond to experimental operation performances. The length of the ejector operation performance is determined by an intersection point of the real I stage backpressure aspect (the real operation performance of the second stage, $\left.P_{\mathrm{s} 2}\right)$ with the line of its critical backpressure, $P_{\mathrm{c} 1}$. The real operation performance of the backpressure of ejector I stage depends on the heat transfer efficiency of the first stage cooler, i.e. particularly on the amount of steam condensed from the steam-air mixture entering a cooler. According to the data of $[1,3], 95-98 \%$ of steam, entering the cooler, should condense.

\section{Ejector design method modifying}

A program was developed for multistage ejector calculation based on the work presented in [2]. The design method, presented in [2], belonging to a semiempirical class designed to calculate the sections of ejector elements such as the primary nozzle, the mixing chamber with a conic entrance and the diffuser, while all the axial dimensions of the device are determined on the basis of the experimentally received recommendations. Considering that the ejector of the condenser system works under a wide range of loads (rates of removed SAM), any special profiling of the ejector elements is not expedient [4].

By calculating the operation performance of an ejector stage with the conical initial section of a mixing chamber on the second limit mode the following relation is used to estimate the value of limit entrainment ratio

$$
u_{\mathrm{cr}}=\left(\mu \frac{F_{3}}{F_{\mathrm{p}^{*}}}-\frac{1}{q_{\mathrm{ps}}}\right) \frac{k_{\mathrm{s}}}{k_{\mathrm{p}}} \cdot \frac{Y_{\mathrm{s}^{*}}}{Y_{\mathrm{p} *}} \cdot \frac{a_{\mathrm{p}^{*}}}{a_{\mathrm{s}^{*}}} \cdot \frac{p_{\mathrm{s}}}{p_{\mathrm{p}}},
$$

where $\mathrm{F}_{3}, \mathrm{~F}_{\mathrm{p}}$ stand for areas of passage section of a mixing chamber cylindrical part and of a primary nozzle throat section;

$\mu$ - the ratio of the cross-section area where the secondary stream reaches the sonic speed $\left(\mathrm{F}_{\mathrm{s}}\right)$ to the cross-section area of mixing chamber cylindrical part $\left(\mathrm{F}_{3}\right)$ (it is assumed that the $\mathrm{F}_{\mathrm{s}}$ plane is located in the conic part of a mixing chamber) ${ }^{1}$;

$k_{\mathrm{s}}, k_{\mathrm{p}}-$ specific heat ratio of secondary and primary streams;

$\mathrm{Y}_{\mathrm{s}^{*}}, \mathrm{Y}_{\mathrm{p}^{*}}$ - the ratios of the sonic isotropic stream of secondary (h) and primary (p) fluids pressures to the stagnation pressure;

$a_{\mathrm{p}^{*}}, a_{\mathrm{s}^{*}}-$ sound speed of the secondary and the primary streams;

$p_{\mathrm{s}}, p_{\mathrm{p}}$ - total pressure of the secondary and the primary streams;

$q_{\mathrm{ps}}-$ gas-dynamic function representing a specified mass speed of the primary stream, it is equal to the areas ratio of primary nozzle throat section and the section of primary stream at a pressure of $p_{\mathrm{H}}$.

A scheme of an ejector with typical sections parameters employed in Equation (1) is shown in fig. 3 .

Agreement between the experimental data and those calculated by the authors method for the ejector on the Fig. 1 was obtained at the value of coefficient $\mu=$ 1.5 . 


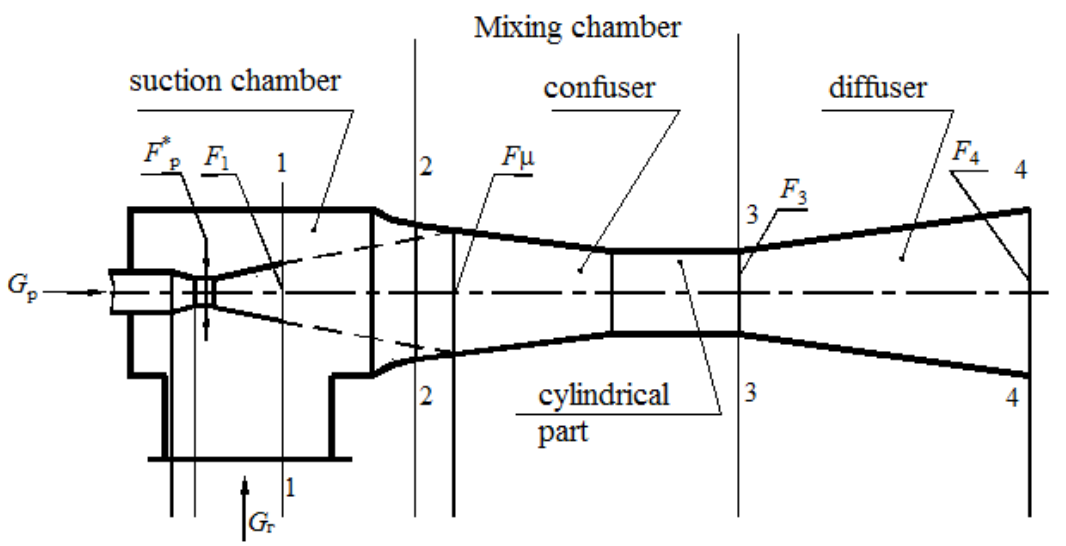

Figure 3: Ejector scheme.

The following feature of the design method of ejector operation performance should also be mentioned. When calculating the ejector entrainment ratio according to (1), $q_{\mathrm{pH}}$, function is determined by the known primary stream pressure ratio $\mathrm{Y}_{\mathrm{ps}}=p / p_{\mathrm{p}}$. This expression was conceived for the conventional process scheme, which does not consider intermixing of streams within the mixing chamber upstream section, provided that static pressures of the primary stream and the secondary stream are not equal.

With this assumption, the calculation corresponds to the ejector operation performance well at $\mathrm{P}_{\mathrm{p}}=1.3-1.6 \mathrm{MPa}$, while the expansion rate of the primary stream is $\beta=1 / \mathrm{Y}_{\mathrm{ps}}=p_{\mathrm{p}} / p_{\mathrm{s}} \approx 230-530$.

The tests of various ejector types carried out by the authors at primary stream pressure of $\mathrm{p}_{\mathrm{p}}=0.5 \mathrm{MPa}(\beta \approx 70-160)$ showed that when calculating the critical entrainment ratio by (1), in the section where the secondary stream velocity reached sonic speed, the specified mass velocity should be determined on the condition of equality of static temperatures in the primary and the secondary streams. In this case $q_{\mathrm{pH}}$ is determined by gas-dynamic function $\mathrm{Y}_{\mathrm{ps}}=\mathrm{Y}_{\mathrm{s}} \cdot p_{\mathrm{s}} / p_{\mathrm{p}}$ (where $Y_{н}$ is the ratio of the isotropic stream of secondary fluid pressure to the stagnation pressure).

This condition concurs with a numerical calculation results obtained by the authors with the use of Star-CCM+ package. This revealed that static pressure in a critical section of an ejector is almost identical both in a primary medium and in a secondary stream (pressure difference near the wall and on the apparatus axis is about $1-3 \%$ ). It should be noted, that the condition of the identity of two static pressures - in primary and in secondary streams - was recommended even by the work of M. D. Millionshikov [2].

\section{The results of an ejector operation performance CFD}

An ejector nominal operation mode $(\mathrm{GB}=80 \mathrm{~kg} / \mathrm{h}$, see Fig. 2) was calculated in Star-CCM+ package. Shown in Fig. 4 is a profile of stream velocities in the jet 
device of an ejector with a supercritical extent of the primary stream expansion and a supercritical extent of mixture compression, as well as the distribution of a static pressure and of specified full velocity (calculated by an absolute vector value) in the direction of a stream flow. The primary steam in the ejector accelerates to supersonic velocities. As a result of such expansion, the pressure in the primary nozzle exit plane decreases from initial $490 \mathrm{kPa}$ to a value of $7 \mathrm{kPa}$, thereby the pressure is creating and backing up a deep rarefaction in the reception and mixing chambers. Typical to normal or oblique pressure shocks arise in the flow core just beyond the primary nozzle in the reception chamber. Diamond shock waves are likely to result from the complex interaction of two media impulses, which are manifested in a series of variations of specified full velocity and static pressure values along the mixing chamber symmetry axis. Such shock waves are possibly the result of the off-design mode of the primary nozzle operation with inadequate expansion (when steam pressure at the primary nozzle outlet exceeds the medium pressure in the mixing chamber). Data, presented in Fig. 4, qualitatively agrees with the results of $[4,5]$ and also of many others.

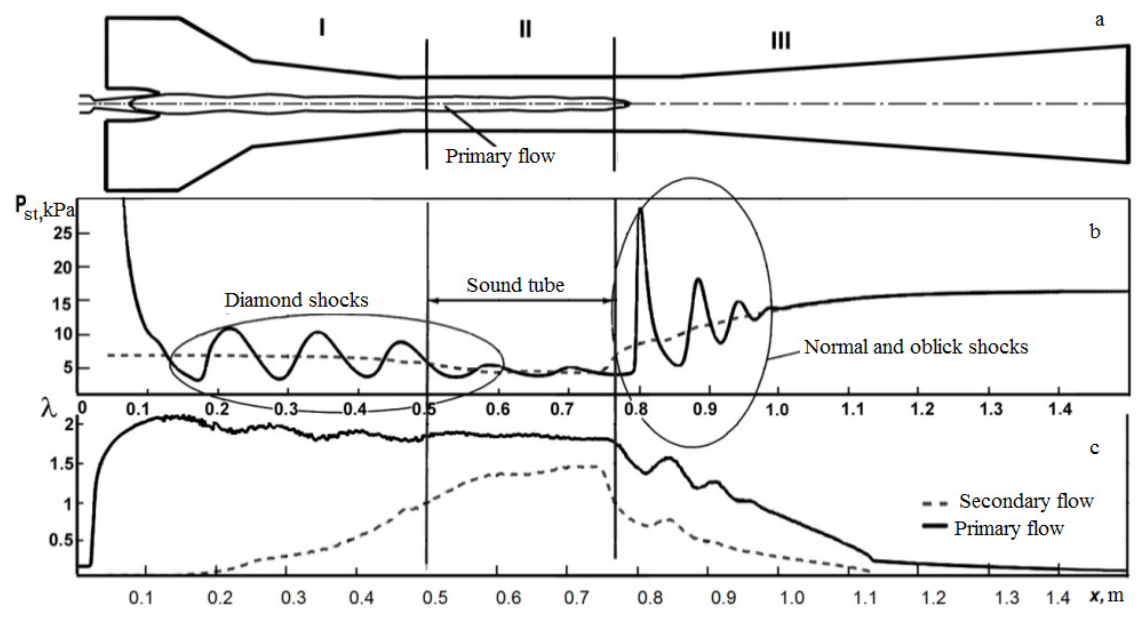

Figure 4: The distribution of the static pressure along the ejector: a - stream shape; b - static pressure distribution; c - reduced velocity distribution; - - - air-steam mixture; — primary steam.

In Fig. 4, $\mathrm{b}$ it is also shown, that in the abscissa axis point $\mathrm{x}=0.5 \mathrm{~m}$, where the value of a secondary stream specified that the full velocity is greater than unity, the pressure shocks decay. This zone (II) extends till $\mathrm{x}=0.78 \mathrm{~m}$. In the author's opinion, pressure shock amplitude decrease is accounted for based on the fact that the primary stream is surrounded by a secondary stream with sonic (supersonic). A "sound pipe" is being created. The "sound pipe" effect on the primary stream can be explained, in the authors' opinion, by the results of the work [6]. Pressure fluctuations, arising in working gas stream, cause border change between primary 
and secondary gases in this zone. Since the cross section of a supersonic flow of the injected gas is limited by the mixing chamber walls, then with the border deformation the pressure impulses arise in it, which are opposite to the primary stream direction, and so they move the border of an injected gas stream back to the primary position.

As a result of continuing stream interaction, the secondary stream's specified full velocity becomes less than 1 (see Fig. 4, c). The "sound pipe" action ends in this section, corresponding to a point of $x \approx 0.78 \mathrm{~m}$, and a second group of pressure shocks arises in the primary stream (the amplitude of this pressure shocks can exceed that of the first zone). The same pattern is described in the work [10], where it is stated, that a strong oblique pressure shock arises in a mixing chamber cylindrical part, destroying the boundary wall layer. This shock is so strong that it causes not only a boundary layer separation (stratification), but also creates a shock train (in the present case there are three of them) with smaller amplitude in an extended diffuser part. To the authors mind, strong pressure shocks after a "sound pipe" section (in a mixing chamber cylindrical part and especially in a diffuser) lead to a wave resistance increasing and to an ejector stage compression ratio decreasing. We also should mention the following fact. In Russian and foreign literature $[2,7,8]$ the zone II, which we call a "sound pipe" zone, is characterized as a zone of active stream mixing. However, in the zone II, as it has been mentioned earlier, primary stream pressure fluctuations decrease. It is logical to assume that the intensity of the transverse mass transfer is also decreasing and, correspondingly, the stream mixing is less, than in zone I.

We assume that the presented gas dynamics pattern of an ejector stream-jet device shows a kind of convention-approximation in coefficient $\mu$ evaluation (employed in (1) equation). This coefficient characterizes the location of a secondary stream limiting section, where a stream reaches sonic velocity due to interaction with the primary stream.

One of the main hypotheses, formulated in the design method of ejectors, using semi-empirical methods, is the hypothesis about the form of the primary stream (gas) jet flowing out of the primary nozzle. In [2] it is recommended to specify a shape of primary stream initial section as a shape of a constant diameter, or as a "diamond" shape, determined by the theory of a free turbulent stream running out of an opening [6]. In [2] it is noted that in the latter case, the results of the critical entrainment ratio calculations are more accurate. However, as it is shown in fig. 4, the sequence of "diamond" shapes of primary flow velocity is in better compliance with a flow model of constant diameter from the primary nozzle and up to the mixing chamber cylindrical part.

\section{Ejector intercondenser's efficiency}

The results of the ejector cooler tests are presented in fig. 5. The ordinate axis shows a portion of steam flow rate, condensed in a I stage cooler, $\delta G_{\mathrm{s}}$, (that is a portion of the full amount of steam entering the cooler), on the abscissa axis it is shown the amount of air in the air-steam mixture $\varepsilon=G_{\mathrm{a}} /\left(G_{\mathrm{a}}+G_{\mathrm{s}}\right)$, where $G_{\mathrm{a}}$ stands for air flow rate, $\mathrm{kg} / \mathrm{sec} ; G_{\mathrm{s}}-\mathrm{I}$ stage primary stream flow rate, $\mathrm{kg} / \mathrm{sec}$. Fig. 5 shows 
that $60 \%-80 \%$ of steam are being condensed in the I stage cooler. If the air amount in an air-steam mixture is $\varepsilon_{\mathrm{a}}>0.1$, then the portion of steam flow, condensed in the I stage cooler, stays nearly constant $\delta G_{\mathrm{s}} \approx 0.7-0.8$ in most experiments.

Fig. 5 also presents a comparison of calculated and experimental data for a portion of steam flow, condensed in the ejector I stage cooler. The calculation of the cooler was performed as described in the work [2]. In addition to described algorithm, a size of a zone was defined of steam overheat removing, which was determined in the experimental investigations as $26 \%-48 \%$ of the full cooler surface area. Air-steam mixture might be strongly overheated in the I stage cooler inlet $\Delta t_{\max }=\left(t_{\mathrm{asm}}-t_{\mathrm{s}}\right) \sim(90-140)^{\circ} \mathrm{C}^{2}$, where $t_{\mathrm{asm}}, t_{\mathrm{s}}$ are the temperature of an airsteam mix and a steam saturation temperature at the corresponding pressure, ${ }^{\circ} \mathrm{C}$.

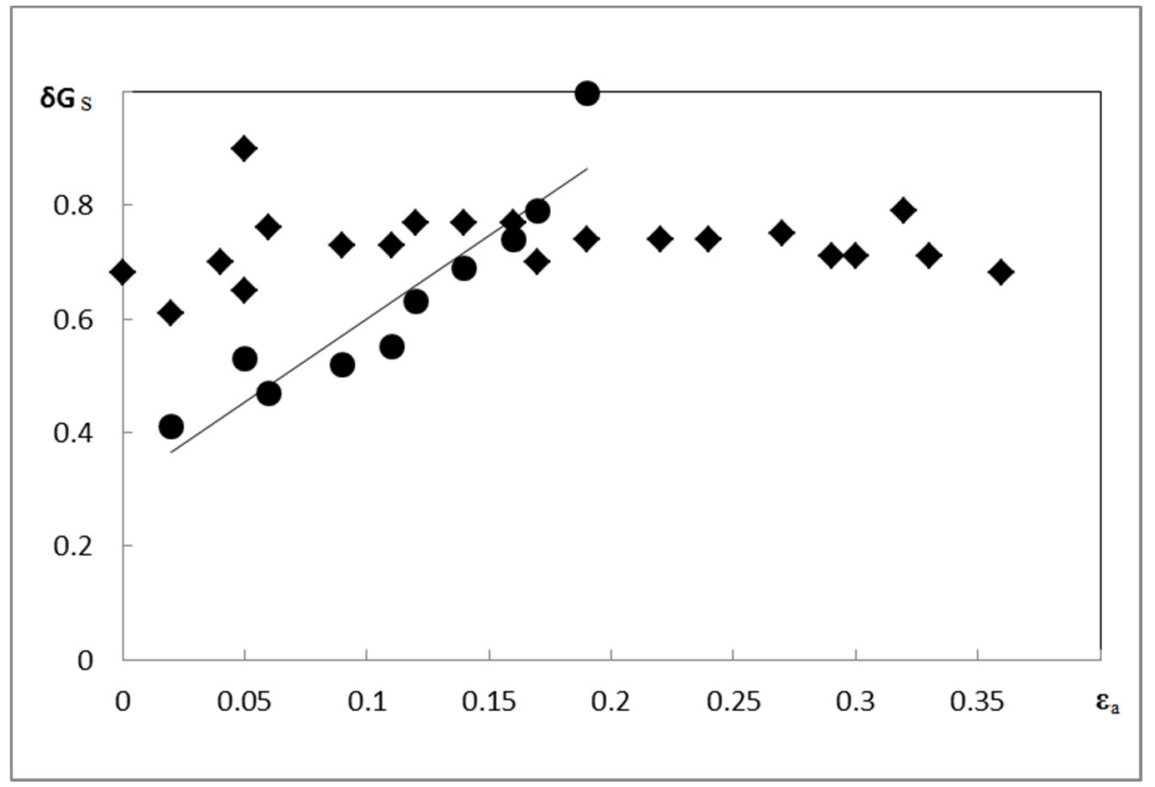

Figure 5: Calculated and experimental data comparison of a steam condensation portion in the ejector I stage cooler at $p_{\mathrm{p}}=0.77 \mathrm{MPa}$ :

- experimental data; • - calculated data; — calculated data approximation.

It should be noted that in accordance with the calculation, $\delta G_{\mathrm{s}}$ increases in the first stage cooler as the air content in ASM rises. This is defined by the fact that the calculation is carried out at the real values of the steam pressure in the cooler. This pressure is defined by the ejector II stage operation performance and it increases along with the amount of air, entering the ejector. With the pressure increasing, the temperature difference between air-steam mixture and cooling water also rises; as a result, the calculated value of $\delta G_{\mathrm{s}}$ in the cooler also increases. However, as it was mentioned above, the actual value of $\delta G_{\mathrm{s}}$ in the cooler stays constant when $\varepsilon_{\mathrm{B}}$ is rising. A discrepancy of calculated and experimental data is 
due, in authors' opinion, to the dynamics of steam condensation in a cooler, and in particular to the fact that the steam does not have enough time to condense in the heat exchanger.

The report presents some assessments for several parameters. The first of them is a duration (time) of steam movement in the cooler intertubular space to a condensation surface $\left(\tau_{j}\right)$, basing on the evaluation of transverse mass flow velocity. The second is a period of steam staying in a cooler, which depends on steam flow velocity in the tube bundle from the cooler inlet to the outlet $\left(\tau_{h}\right)$. According to calculations, $\tau_{j}=(0.010-0.038)>\tau_{h}=(0.008-0.0188)$, the maximum time of transverse mass flow moving to the condensation surface is greater than the duration of steam moving in the tube bundle from the inlet to the outlet.

\section{Conclusion}

Based on the analysis of experimental operation performances of 27 multistage steam-driven ejectors, a set of problems was developed to refine the physical simulation of the processes in the ejector.

1. A secondary flow is accelerated by a primary flow to supersonic velocities in a mixing chamber. Pressure shocks in a primary stream decrease in this "sound tube" zone. After a secondary stream velocity decreasing to less than critical values, the pressure shocks in a primary stream appear again.

2. The use of parameter $\mu$ values recommended in literature ( $\mu$ determines the ratio of the mixing chamber convergent part cross-section area, where the secondary flow reaches sonic speed, to the area of mixing chamber cylindrical part cross-section) does not guarantee a satisfied agreement of ejector I stage calculated operation performance and the experimental operation performance.

3. For an entrainment ratio calculation at a second limit mode of turbine threestage steam-driven ejectors with working steam pressure of $0.5 \mathrm{MPa}$, it is necessary to presume the equality of pressures of the primary and secondary streams in the zone where the secondary flow reaches a critical velocity.

4. The length of an operation performance is defined by the fact, that only 70$80 \%$ of steam, entering the first stage cooler, condense there. A portion of steam flow condensed in the cooler is determined by a ratio of steam condensation rate (of the velocity of transverse mass flow to a condensing surface) and an air-steam mixture velocity in the tube bundle. 


\section{References}

[1] G.G. Shklover. The Influence of Injected Gas Properties and Parameters on Steam Ejector Operation. G. G. Shklover, O. O. Milman, A.V. Gerasimov, A.G. Kaptilny/ Teploenergetika. 1975. No. 12. Page 55-59.

[2] Sokolov E.Ya. Jet-Stream Apparatuses. Sokolov E.Ya., Zinger N.M. Energoatomizdat, 1968. 352 p.

[3] Aronson K.E. Research of Gas Dynamics in Steam Ejector Apparatuses. Aronson K.E., Brezgin D.V., Murmanskii I.B. et al. Theses of the Fifth conference "Heat exchange and gas dynamics in crew flows". Kazan, October, 19-22, 2015, pp. 166-167.

[4] K. Pianthong, W. Seehanam, M. Behnia, T. Sriveerakul, S. Aphornratana. Investigation and improvement of ejector refrigeration system using computational fluid dynamics technique. Energy Conversion and Management №48 (2007) pp. 2556-2564.

[5] Yinhai Zhua, Wenjian Caia, Changyun Wena. Simplified ejector model for control and optimization. Energy Conversion and Management №49 (2008), pp. 1424-1432.

[6] Abramovich G.N. Applied Gas Dynamics. Science, 1991. 600 p.

[7] Shock train and pseudoshock phenomena in internal gas flows. Matsuo, K., Miyazato, Y., Kim, H.-D., 1999. Progr. Aerospaces №35, 33-100.

[8] Numerical and experimental investigations on supersonic ejectors. Y. Bartosiewicz, Zine Aidoun, P. Desevaux, Yves Mercadier. International Journal of Heat and Fluid Flow №26 (2005) 56-70. 